\title{
Antimalarial Drug Susceptibility Testing of Plasmodium falciparum in Brazil Using a Radioisotope Method
}

\author{
Crispim Cerutti Junior, Christiane Marques*, Filomena EC de Alencar, Rui \\ Rafael Durlacher, Anna Alween*, Aluísio AC Segurado, Lorrin W Pang*, \\ Mariano G Zalis**/+
}

\begin{abstract}
Departamento de Doenças Infecciosas e Parasitárias, Universidade de São Paulo, São Paulo, SP, Brasil *United States Army Medical Research Unit, Rio de Janeiro, RJ, Brasil **Instituto de Biofísica Carlos Chagas Filho, Bloco G, CCS, Universidade Federal do Rio de Janeiro, Ilha do Fundão, 21949-900 Rio de Janeiro, RJ, Brasil
\end{abstract}

From March 1996 to August 1997, a study was carried out in a malaria endemic area of the Brazilian Amazon region. In vivo sensitivity evaluation to antimalarial drugs was performed in 129 patients. Blood samples $(0.5 \mathrm{ml})$ were drawn from each patient and cryopreserved to proceed to in vitro studies. In vitro sensitivity evaluation performed using a radioisotope method was carried out with the cryopreserved samples from September to December 1997. Thirty-one samples were tested for chloroquine, mefloquine, halofantrine, quinine, arteether and atovaquone. Resistance was evidenced in 96.6\% (29/30) of the samples tested for chloroquine, 3.3\% (1/30) for quinine, none (0/30) for mefloquine and none for halofantrine (0/30). Overall low sensitivity was evidenced in $10 \%$ of the samples tested for quinine, $22.5 \%$ tested for halofantrine and in $20 \%$ tested for mefloquine. Means of IC 50 values were 132.2 (SD: 46.5) $\mathrm{ng} / \mathrm{ml}$ for chloroquine, 130.6 (SD: 49.6) $\mathrm{ng} / \mathrm{ml}$ for quinine, 3.4 (SD: 1.3 ) $\mathrm{ng} / \mathrm{ml}$ for mefloquine, 0.7 (SD: 0.3) $\mathrm{ng} / \mathrm{ml}$ for halofantrine, 1 (SD: 0.6) $\mathrm{ng} / \mathrm{ml}$ for arteether and 0.4 (SD: 0.2) $\mathrm{ng} / \mathrm{ml}$ for atovaquone. Means of chloroquine IC 50 of the tested samples were comparable to that of the chloroquine-resistant strain $W 2(137.57 \mathrm{ng} / \mathrm{ml})$ and nearly nine times higher than that of the chloroquine-sensitive strain D6 (15.09 $\mathrm{ng} / \mathrm{ml})$. Means of quinine IC 50 of the tested samples were 1.7 times higher than that of the low sensitivity strain W2 $(74.84 \mathrm{ng} / \mathrm{ml})$ and nearly five times higher than that of the quinine-sensitive strain D6 $(27.53 \mathrm{ng} / \mathrm{ml})$. These results disclose in vitro high resistance levels to chloroquine, low sensitivity to quinine and evidence of decreasing sensitivity to mefloquine and halofantrine in the area under evaluation.

Key words: Plasmodium falciparum - drug resistance - drug test - chloroquine - quinine - mefloquine

Malaria is one of the biggest health problems in the world. It is responsible for 500 million new cases worldwide each year, with 1.5 to 2.7 million deaths (Kondrachine \& Trigg 1997). The disease is distributed in the tropical areas, afflicting the developing countries, where it becomes an important obstacle to the efforts of economic development (Kondrachine \& Trigg 1997).

Almost all of the malaria cases in Brazil are reported from the Amazon Region (Marques 1993) where migrant populations, great distances, and poor access to diagnosis and treatment are major barriers to malaria control. Malaria prevalence in Brazil has increased three times during the past

\footnotetext{
${ }^{+}$Corresponding author. Fax: +55-21-280.8193. E-mail mgzalis@ibccf.biof.ufrj.br Received 22 February 1999 Accepted 2 September 1999
}

decade, to nearly 500,000 cases each year (FNS 1995). Migrant populations disseminate resistant strains throughout the region and lead them to malaria free areas, increasing the risks of outbreaks (Marques 1986). Plasmodium falciparum drug resistance in Brazil has developed at an alarming rate to chloroquine, Fansidar ${ }^{\circledR}$ and to some extent quinine (Boulos et al. 1986). As vector control is not a realistic approach in this region, early diagnosis and effective treatment are essential tools for control strategies. Apart from the availability of a wellstructured network of diagnosis facilities, the choice for adequate drugs is of crucial importance. The identification of adequate drugs, however, depends on a solid knowledge of the resistance pattern in the various endemic areas.

In vitro studies in Brazil have been conducted using morphology-techniques (Alecrim 1986, Di Santi et al. 1988, Kremsner et al. 1989). These techniques are less expensive than the radiosotopic ones, but are also more prone to subjective misinterpretation. "Cut off" limits used for mefloquine 
and quinine in those studies were too low, leading to overestimation of the resistance percentages (Alecrim 1986, Di Santi et al. 1988) When adequate "cut off" limits are employed, taking together in vivo and in vitro data, parasite resistance has been observed at levels greater than $70 \%$ to chloroquine, greater than $60 \%$ to sulfadoxine-pyrimethamine, lower than $20 \%$ to quinine and almost none to mefloquine (Boulos et al. 1986, Alecrim 1986, Di Santi et al. 1988, Kremsner et al. 1989, Souza 1992, Couto et al. 1993). As in vitro evaluations of $P$. falciparum sensitivity have not been performed since the 80's (Di Santi et al. 1988, Kremsner et al. 1989), and considering that radioisotopic methods had not been used, except in one occasion (Zalis et al. 1998), we decided to verify the patterns of resistance in a typical endemic area of the Brazilian Amazon region.

\section{MATERIALS AND METHODS}

Study area - Peixoto de Azevedo municipality is located at the northern part of the State of Mato Grosso, $700 \mathrm{~km}$ north from the State capital, at the southern fringe of the Amazon basin. Its population is estimated in about 37,000 inhabitants. The main economic activities are gold mining, farming and logging. The climate is Equatorial, with two seasons: rainy season from November to April, and dry season from May to October. Three hundred malaria cases were reported per week in 1993/ 1994, about 50\% P. falciparum. Malaria transmission is stable around the year, with some increase in the rainy season.

Inclusion criteria - Adult male patients 18 years old or older, with a positive thick smear for $P$. falciparum and a parasite count equal to or greater than 1,000 ring forms $/ \mu \mathrm{l}$ who agreed to give informed consent, were considered eligible for the study.

Exclusion criteria - Patients were considered inadequate for the study if they had taken quinine or mefloquine in the preceding seven days, had clinical or laboratory evidences of cerebral or severe malaria (alterations of consciousness, severe jaundice, breath shortening, oliguria, hemoglobin $\leq 7 \mathrm{~g} \%$, parasite count greater than 100,000 ring forms/ $\mu \mathrm{l}$, serum bilirrubin levels greater than $5 \mathrm{mg} /$ $\mathrm{dl}$ or greater than $2.5 \mathrm{mg} / \mathrm{dl}$ in case of direct bilirrubin greater than $1 \mathrm{mg} / \mathrm{dl}$, ALT or AST $\geq 100 \mathrm{U} / \mathrm{l}$, urea greater than $100 \mathrm{mg} / \mathrm{dl}$, creatinine greater than 2 $\mathrm{mg} / \mathrm{dl}$ ), had mixed plasmodial infection. Such exclusion criteria are not directly necessary for the in vitro test. They were applied for the selection of the patients admitted to the in vivo study, from which a subset of samples was used in the in vitro method.

Processing of blood specimens - Upon admission to the in vivo study, $10 \mathrm{ml}$ aliquots of whole blood were collected from each patient. Specimens were used in baseline laboratory evaluation, in vitro morphology-technique tests and cryopreserved for future in vitro radioisotope testing. For cryopreservation, $0.5 \mathrm{ml}$ of packed red cells were mixed with $0.5 \mathrm{ml}$ of Glycerolite 57 Solution ${ }^{\circledR}$ (Travenol Lab.) (ingredients in $100 \mathrm{ml}: 57 \mathrm{~g}$ glycerine, $1.6 \mathrm{~g}$ sodium lactate, $30 \mathrm{mg}$ potassium chloride and $25 \mathrm{mEq} / \mathrm{l} \mathrm{so-}$ dium phosphates) and placed in liquid nitrogen. These procedures were done at the study site. Stored samples were transported to Rio de Janeiro where the tests were performed.

Thirty-one specimens taken at random from those initially cryopreserved were used to perform the tests.

Aliquots for in vitro radioisotope testing were removed from storage and thawed at room temperature. The thawed red blood cell suspension was quickly added to $0.4 \mathrm{ml}$ hypertonic sterile $12 \%$ saline solution, mixed well, and left in rest during $5 \mathrm{~min}$. The sediment was added to $9 \mathrm{ml}$ hypertonic sterile $1.6 \%$ saline solution, mixed well, and centrifuged (320 $\mathrm{g}, 5 \mathrm{~min})$. The supernatant was decanted and the procedure was repeated with sterile $0.9 \%$ saline solution. After the last centrifugation, sample red blood cells were suspended in complete medium (RPMI 1640 + heat-inactivated $\mathrm{A} \oplus$ plasma) + 50\% suspension of normal $\mathrm{A} \oplus$ red blood cells in RPMI 1640 medium (final cell suspension 5\%) and cultured in a $\mathrm{CO}_{2}$ enriched atmosphere $\left(5 \% \mathrm{CO}_{2}\right)$. Drug testing was performed using the cultured parasites once the parasitemia of the culture reached an optimum density ( $0.5 \%$ to $1 \%$ parasitized red blood cells).

In vitro drug testing using the radioisotope technique - The procedure used was essentially that of Desjardins et al. (1979). Five milligrams of each drug to be tested were diluted in $70 \%$ ethanol to a final concentration of $1 \mathrm{mg} / \mathrm{ml}$, except for chloroquine which one was diluted in distilled water. These solutions were used as stock solutions. The stock solutions were further diluted in complete medium without hypoxanthine in order to keep the following serial dilutions $(\mathrm{ng} / \mathrm{ml})$ :

arteether, atovaquone and halofantrine: 25 - 8.33 $2.77-0.92-0.3-0.1-0.03$

mefloquine: 250 - 83.3 - $27.7-9.25$ - 3.08 - $1.02-0.34$ chloroquine and quinine: 2500 - 833.3 - 277.7 - 92.5 - 30.8 - 10.2 - 3.4

Drugs were kindly provided by Walter Reed Army Institute of Research.

Each isolate was tested one time in duplicate for all drugs. Twenty-five microlitres of each drug dilution were dispensed into the wells of a standard microtiter plate (96 flat bottom wells, 8 x 12 matrix). A suspension of malaria infected red blood cells was also dispensed $(200 \mu \mathrm{l})$ into the same wells. Control wells (without drug) were filled with either 
parasitized (positive controls) or normal (negative controls) red blood cells (1\% suspension in complete medium without hypoxanthine). Seeded plates were incubated in $5 \% \mathrm{CO}_{2}, 37^{\circ} \mathrm{C}$ temperature. Following $24 \mathrm{hr}$ incubation the microtiter plates were removed from the incubator and pulsed with $\left({ }^{3} \mathrm{H}\right)$-hypoxanthine (specific activity $1 \mathrm{Ci} / \mathrm{mMol}$ ) by addition of $25 \mu \mathrm{l}(0.5 \mu \mathrm{Ci})$ of the isotope solution to each well. Microtiter plates were then returned to the incubator for another $24 \mathrm{hr}$. After the second period of incubation, the microtiter plates were frozen to $-70^{\circ} \mathrm{C}$ and thawed, to provide red blood cells lysis. Each plate was harvested after thawing on a Basic 96 Harvester ${ }^{\circledR}$ (Skatron Instruments).

The filter strip disks were dried and placed in a Liquid Scintillation Counter (1205 Betaplate).

Data analysis - Concentration-response data were analyzed by a nonlinear regression function using the NFIT computer program (University of Texas Medical Branch, Galveston, TX) to determine the 50\% inhibitory concentration (IC 50). The IC 50 is defined as that concentration of drug producing a $50 \%$ inhibition of uptake of $\left({ }^{3} \mathrm{H}\right)$-hypoxanthine by the intraerythrocytic parasites. All drug concentrations were expressed as nanograms/milliliter (ng/ml).

The following IC 50 values were considered discriminative for resistance (Webster et al. 1985, Wongsrichanalai et al.1992a, Le Bras 1995):

chloroquine: greater than $45.5 \mathrm{ng} / \mathrm{ml}(\sim 100 \mathrm{nM})$ quinine: greater than $275 \mathrm{ng} / \mathrm{ml}(\sim 500 \mathrm{nM})$ mefloquine: greater than $10 \mathrm{ng} / \mathrm{ml}(\sim 24 \mathrm{nM})$ halofantrine: greater than $2 \mathrm{ng} / \mathrm{ml}(\sim 4 \mathrm{nM})$

Arteether and atovaquone discriminative values are still not well-established.

Reference strains W2 (chloroquine-resistant, mefloquine-sensitive), D6 (chloroquine-sensitive, mefloquine-resistant) and HB3 (chloroquine-resistant, mefloquine-sensitive) were simultaneously tested for the same drugs for comparison. Isolates were considered of low sensitivity to quinine, halofantrine or mefloquine if their IC 50s were higher than the upper limit for the standard deviation of the corresponding means.

Isolates were considered of low sensitivity to quinine, halofantrine or mefloquine if their IC 50s were higher than the upper limit for the standard deviation of the corresponding means.

It was verified the correlation between IC 50s of the several tested isolates and in vivo parasite clearance times determined both by thick smear and QBC®. The correlation was verified by simple linear regression. Statistical significance was tested by "Student" t test.

Correlation between mefloquine and quinine IC 50s, and between mefloquine and halofantrine
IC 50s were also verified by simple linear regression, statistical significance being tested by "Student" t test.

Statistical analysis was made using EPI INFO 6 version 6.02 (Centers for Disease Control and Prevention - CDC, USA) statistic software.

\section{RESULTS}

From March 1996 to August 1997, 129 patients were evaluated in the in vivo study. Ninety-six were tested for mefloquine sensitivity from March 1996 to January 1997, and 33 were tested for quinine sensitivity from January to August 1997. Cure rates were $97.9 \%$ (94/96) for mefloquine and $100 \%$ (33/33) for quinine (detailed results from this study will be published elsewhere).

From September to December 1997, 31 cryopreserved samples were tested for in vitro sensitivity to the following drugs: chloroquine (30 samples), quinine (30 samples), mefloquine (30 samples), halofantrine (31 samples), arteether (30 samples) and atovaquone (30 samples).

Resistance was evidenced in $96.6 \%$ (29/30) of the samples tested for chloroquine, $3.3 \%$ (1/30) for quinine, none $(0 / 30)$ for mefloquine and none $(0 /$ 31) for halofantrine. Isolates were considered of low sensitivity to quinine, halofantrine or mefloquine if their IC 50s were higher than the upper limit for the standard deviation of the corresponding means. Low sensitivity was evidenced in $10 \%$ of the samples tested for quinine, in $20 \%$ tested for mefloquine and in $22.5 \%$ tested for halofantrine (Fig. 1).

Means of IC 50 values were 132.2 (SD: 46.5) (range: 45.5 - 286.7) $\mathrm{ng} / \mathrm{ml}$ for chloroquine, 130.6 (SD: 49.6) (range: $45.2-275.8) \mathrm{ng} / \mathrm{ml}$ for quinine, 3.4 (SD: 1.3) (range: $1.2-6.4) \mathrm{ng} / \mathrm{ml}$ for mefloquine, 0.7 (SD: 0.3) (range: $0.4-1.5$ ) $\mathrm{ng} / \mathrm{ml}$ for halofantrine, 0.4 (SD: 0.2) (range: $0.09-0.8) \mathrm{ng} / \mathrm{ml}$ for atovaquone and 1 (SD: 0.6) (range: $0.3-2.63) \mathrm{ng} / \mathrm{ml}$ for arteether. IC 50 values for atovaquone were low for all the tested samples. A broad variation of IC 50 values for arteether was observed among the tested samples.

Means of chloroquine IC 50 of the tested samples were comparable to that of the chloroquineresistant strain $\mathrm{W} 2(137.57 \mathrm{ng} / \mathrm{ml})$ and nearly nine times higher than that of the chloroquine-sensitive strain D6 $(15.09 \mathrm{ng} / \mathrm{ml})$. Means of quinine IC 50 of the tested samples were 1.7 times higher than that of the low sensitivity strain W2 $(74.84 \mathrm{ng} / \mathrm{ml})$ and nearly five times higher than that of the quininesensitive strain D6 $(27.53 \mathrm{ng} / \mathrm{ml})$. When compared to the chloroquine-sensitive/quinine-sensitive strain HB3, IC 50 values of the tested samples were almost 70 times higher for chloroquine (HB3: $1.93 \mathrm{ng} / \mathrm{ml}$ ) and 2.7 times higher for quinine (HB3: $48.38 \mathrm{ng} / \mathrm{ml}$ ). 

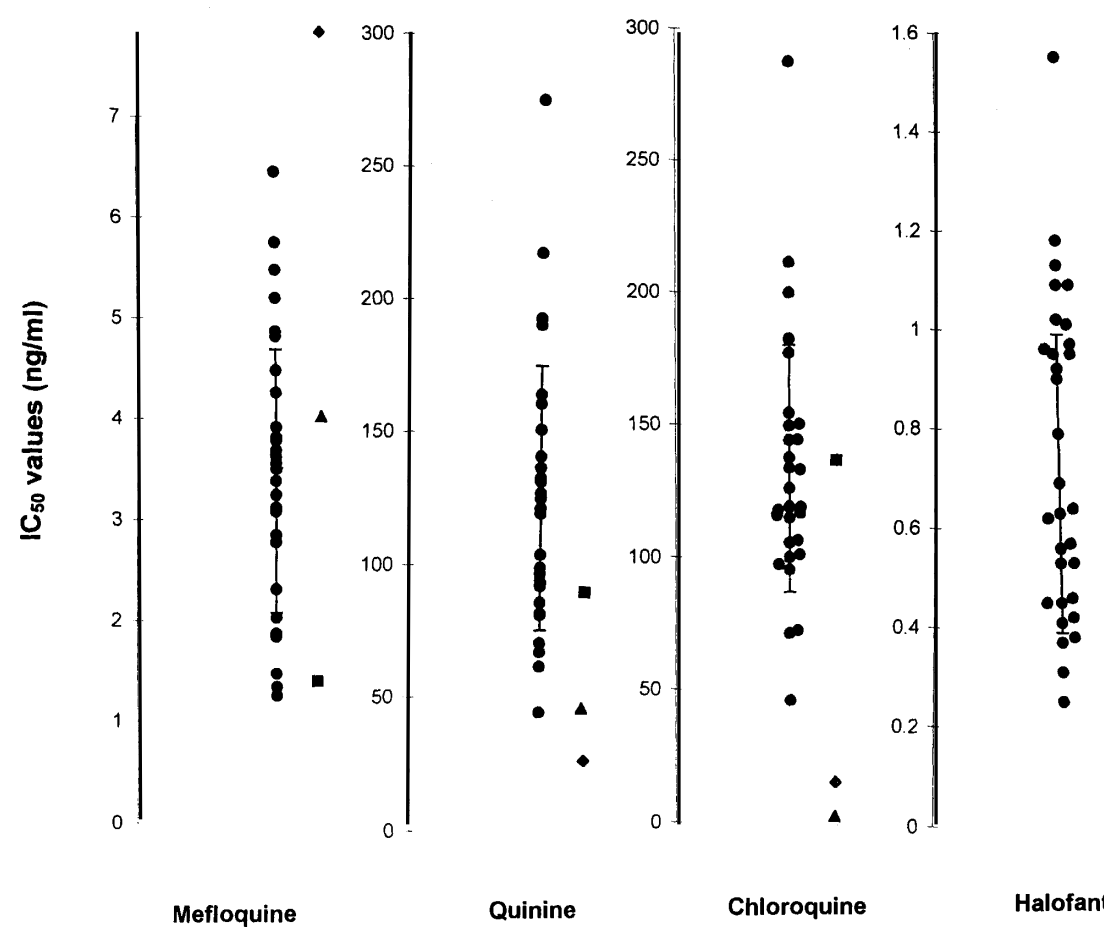

Quinine

Chloroquine

Halofantrine

Fig. 1: distribution of IC50 values $(\mathrm{ng} / \mathrm{ml})$ for mefloquine, quinine, chloroquine and halofantrine in 30 tested samples using a radioisotope technique. Values are individual IC50 (ng/ml). Bars define standard deviation for the means. Plasmodium falciparum D6 (chloroquine sensitive, mefloquine resistant), W2 (chloroquine resistant, mefloquine sensitive) and HB3 (chloroquine sensitive, mefloquine sensitive) were used as standard controls for IC50 values.

There was good correlation between IC 50 values in vitro and parasite clearance time in vivo, as determined by QBC® test, for those cases treated with quinine ( $\mathrm{n}=4, \mathrm{r}=0.94, \mathrm{t}=8.29, \mathrm{n}-2 \mathrm{df}, \mathrm{p}<0.05)$. There was no correlation, however, between IC 50 values and parasite clearance time as determined by thick smear for those cases treated with quinine $(n=8$, $\mathrm{r}=0.08, \mathrm{t}=0.22, \mathrm{n}-2 \mathrm{df}, \mathrm{p}>0.05$ ) or between IC 50 values and parasite clearance times determined either by thick smear $(\mathrm{n}=21, \mathrm{r}=0.17, \mathrm{t}=0.75, \mathrm{n}-2 \mathrm{df}, \mathrm{p}>0.05)$ or QBC® test ( $\mathrm{n}=21, \mathrm{r}=25, \mathrm{t}=1.13, \mathrm{n}-2 \mathrm{df}, \mathrm{p}>0.05)$ for those cases treated with mefloquine (Fig. 2).

Statistically significant positive correlation was also observed between mefloquine and quinine IC $50 \mathrm{~s}(\mathrm{n}=29, \mathrm{r}=0.55, \mathrm{t}=3.43, \mathrm{n}-2 \mathrm{df}, \mathrm{p}<0.05)$, but not between mefloquine and halofantrine IC 50s $(n=30$, $\mathrm{r}=0.33, \mathrm{t}=1.85, \mathrm{n}-2 \mathrm{df}, \mathrm{p}>0.05$ ).

Morphology-technique tests were also simultaneously performed in this study population (manusc. in prep.). In the present situation, eleven isolates were tested by both methods. Resistance percentage to chloroquine evidenced by the morphologic test was quite similar to that demonstrated by the radioisotopic test $(97.8 \%$ vs. $96.6 \%$, respectively), as it was the low sensitivity percentage to quinine (10.6\% vs. $10 \%$, respectively). Regarding mefloquine, it was not possible to determine accurately the sensitivity pattern in the morphologic test because of methodology problems.

\section{DISCUSSION}

$P$. falciparum resistance to antimalarial drugs has become a big concern for those dealing with malaria control strategies. New drugs are necessary approximately each ten years to keep therapeutic approaches efficacious. Chloroquine is no longer useful in almost all the areas afflicted by falciparum malaria (Kondrachine \& Trigg 1997). Resistance to sulfadoxine-pyrimethamine is disseminated in South America and Southeast Asia, and is also increasing in Africa (Wolday et al. 1995). Mefloquine, once considered a safe and efficacious drug, had met the same fate of parasite resistance in Southeast Asia and other regions of the world (Oduola et al. 1987, Brasseur et al. 1992, Fontanet et al. 1993). Effective treatment, one of the cornerstones of the malaria control strategies, has been severely impaired as resistance develops to the standard therapeutic schedules. In order to avoid such a impairment, resistance monitoring is of uppermost importance, at best by in vivo and in vitro methods. 

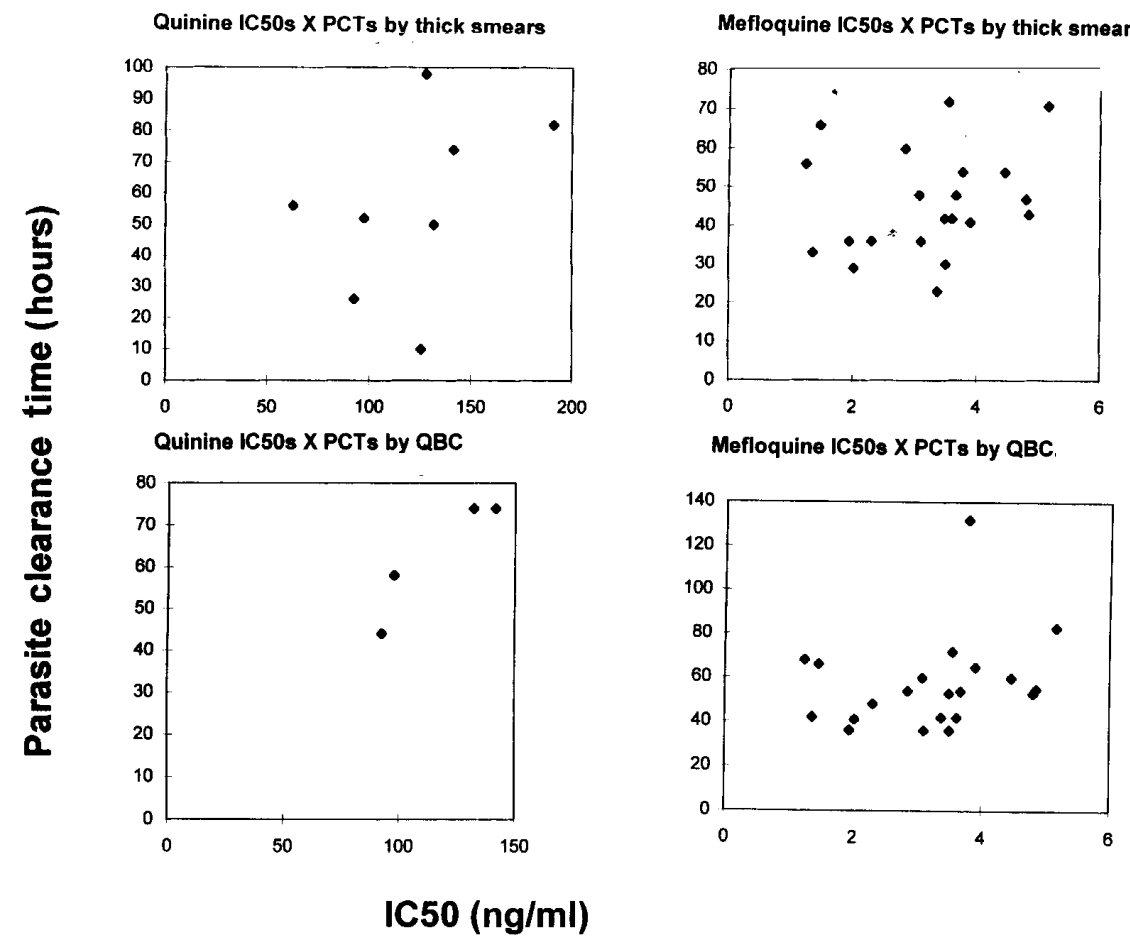

Fig. 2: correlation among either quinine or mefloquine IC50 and parasite clearance time determined by either thick smear or QBC test.

The present study confirmed the high level of resistance to chloroquine previously demonstrated in other areas of the Amazon basin (Boulos et al. 1986, Alecrim 1986, Di Santi et al. 1988, Zalis et al. 1998). Regarding quinine, besides the low true-resistance percentage observed (3.3\%), IC 50s to the tested samples were as high as those observed in other areas of the world with decreased susceptibility (Webster et al. 1985), suggesting that the usefulness of the drug will not last for a long time. As a consequence, while the drug is still efficacious for immune patients curing $100 \%$ of 33 so treated (manusc. in prep.), there is a high risk of failure in the non-immune.

As for mefloquine and halofantrine, a significant percentage of the tested samples presented low sensitivity (20\% and $22.5 \%$, respectively). A decrease in mefloquine in vitro sensitivity could not be triggered by its uncontrolled use, once the access to the drug is restricted in the region. However, one possible explanation for such a decrease could be cross-resistance to quinine. Inadequate quinine use could have selected less sensitive parasites which, in turn, could present incipient crossresistance to mefloquine (Suebsaeng et al. 1986, Warsame et al. 1991, Brasseur et al. 1992). In fact, a significant positive correlation was found between mefloquine and quinine IC 50s. Cross-resistance has also been reported between mefloquine and halofantrine (Cowman et al 1994). In the present study, however, apart from a similar low sensitivity percentage, no correlation was found between mefloquine and halofantrine IC 50s. Nevertheless, there must be some relationship between quinine, mefloquine and halofantrine sensitivity, as the last drug was never used in Brazil in a population basis, preventing any possibility of selection pressure.

IC 50s for atovaquone were low as expected, once this is a new drug never used for treatment of the disease. The significance of the broad variation observed in the IC 50 values for arteether cannot be adequately understood because discriminative values for resistance are not well-established. Resistance and low sensitivity percentages obtained by the morphology technique approached those obtained by the radioisotope method. Similar results have been observed when both techniques are used simultaneously, however they are not directly comparable (Webster et al. 1985, Wongshrichanalai et al. 1992b). The similarity in the results obtained by both techniques is encouraging, as the morphology-techniques are much less expensive and easier to perform. As a consequence, they are widely employed in the field, allowing for in vitro studies of fresh isolates. The ideal situation would be if resistance could be moni- 
tored in the various study sites by the morphology technique, which results would be counter-checked by the radioisotope testing in a reference center.

Morphology-technique tests were also simultaneously performed in this same study population (manusc. in prep.). Similar results have been observed when both techniques are used simultaneously, however they are not directly comparable (Webster et al. 1985, Wongsrichanalai et al. 1992 a,b). In the present situation, eleven isolates were tested by both methods. Resistance percentage to chloroquine evidenced by the morphologic test was quite similar to that demonstrated by the radioisotopic test (97.8\% vs. $96.6 \%$, respectively), as it was the low sensitivity percentage to quinine $(10.6 \%$ vs. $10 \%$, respectively). Regarding mefloquine, it was not possible to determine accurately the sensitivity pattern in the morphologic test because of methodology problems. The similarity in the results obtained by both techniques is encouraging, as the morphology-techniques are much less expensive and easier to perform. As a consequence, they are widely employed in the field, allowing for in vitro studies of fresh isolates. The ideal situation would be if resistance could be monitored in the various study sites by the morphology technique, which results would be counter-checked by the radioisotope testing in a reference center.

No correlation was found between IC 50 in vitro and parasite clearance times evaluated by two methods in vivo, except for four patients treated with quinine and evaluated by QBC $®$ test. Besides previous evidence of enlargement of parasite clearance time associated to the upsurge of resistance either in vivo or in vitro (Fox et al. 1985, Warsame et al. 1991, Barkakaty et al. 1992) no correlation has been found when quantitative parameters are directly compared, such as minimum inhibitory concentration versus parasite clearance time or IC 50 versus parasite clearance time (Sowonmi et al. 1992, Alin et al. 1995). It can be in part explained by the complex host-parasite relationship. The immune response of the infected individual concurs for the parasite clearance, preventing its direct correlation with the drug inhibitory capability. Other factor that could have contributed for the absence of correlation is the small number of patients evaluated simultaneously in vivo and in vitro to the same drugs. Such absence of correlation seems to imply that in vivo outcome can not be predicted by in vitro parameters.

The population sample comprised young males that had experienced several malaria episodes along their lives. Most of them were miners, with a nomadic behavior, "transporting" resistant parasites from region to region. They are refractory to rules and, as a consequence, bad compliers to long last- ing therapeutic schedules, especially those with multiple daily intakes. The previous experience with malaria confers some immunity to them, making parasite clearance easier. This population takes part in the development and dissemination of resistance and should be the target for the malaria control strategies. Nevill et al. stressed the importance of evaluating antimalarial drugs' sensitivity in high risk groups, what they called "real life situation" (Nevill et al. 1995)

Quinine is frequently used in association with other drugs like tetracycline or doxycycline, in long lasting schedules that discourage compliance. This is the case for the Brazilian Amazon. This practice results in high levels of abandonment by treated patients. Half the patients treated with quinine and tetracycline in Peixoto de Azevedo do not comply for more than three days (de Alencar, unpub. obs.). Low compliance allows for resistance selection. Parasites so selected generate gametocytes with the resistance trait, which ones will be transmitted by infective mosquitoes, amplifying the resistant reservoir (Wernsdorfer 1992). Cross-resistance with mefloquine and halofantrine will limit their time of availability as useful drugs. These events explain the generalized low sensitivity observed for the three drugs in the present study.

Mefloquine is being considered for more extensive use in Brazil as a way to improve compliance and render malaria control more efficient. The generalized use of mefloquine will probably hasten resistance development, in a similar way as happened in Southeast Asia in the beginning of this decade (Fontanet et al. 1993). After mefloquine, the therapeutic alternative will be artemisinin derivatives, beyond which there will be few drugs whose performances in a population basis are not well known. After mefloquine, the last therapeutic alternative will be artemisinin derivatives, beyond which there will be no available treatment for the disease. Such a worrying situation makes urgent the search for new therapeutic alternatives to deal with this dangerous parasitic disease in the Brazilian Amazon region.

\section{REFERENCES}

Alecrim MG 1986. Resistance to in vivo and in vitro chemotherapies in the Brazilian Amazonia. Mem Inst Oswaldo Cruz 81: 153-157.

Alin MH, Kihania CM, Bjorkman A, Bwijo BA, Premji Z, Mtey GJB, Ashton M 1995. Efficacy of oral and intravenous artesunate in male Tanzanian adults with Plasmodium falciparum malaria and in vitro susceptibility to artemisinin, chloroquine, and mefloquine. Am J Trop Med Hyg 53: 639-645.

Barkakaty BN, Narasimhan MVVL 1992. A longitudinal study to monitor chloroquine-resistant $P$. falciparum malaria in Bokajan and Manja PHC areas 
of Karbi Anglong District, Assam. Indian J Malariol 29: $173-183$

Boulos M, Di Santi SM, Barata LCB, Segurado AAC, Dutra AP, Neves VLFC 1986. Some aspects of treatment, prophylaxis and chemoresistance of Plasmodium falciparum malaria. Mem Inst Oswaldo Cruz. 81: 225-257.

Brasseur P, Kouamouo J, Moyou-Somo R, Druilhe P 1992. Multi-drug resistant falciparum malaria in Cameroon in 1987-1988 II. Mefloquine resistance confirmed in vivo and in vitro and its correlation with quinine resistance. Am J Trop Med Hyg 46: 8-14.

Couto AA, Calvosa VS, Santos MA, Souza JM 1993. Resistência in vitro de cepas do Plasmodium falciparum isoladas no sul do estado do Pará, em diferentes períodos: emergência de casos de multirresistência. Rev Soc Bras Med Trop 26: 5-9.

Cowman AF, Galatis D, Thompson J 1994. Selection for mefloquine resistance in Plasmodium falciparum is linked to amplification of the pfmdrl gene and cross-resistance to halofantrine and quinine. Proc Natl Acad Sci USA 91: 1143-1147.

Desjardins RE, Canfield CJ, Haynes JD, Chulay JD 1979. Quantitative assessment of antimalarial activity in vitro by a semiautomated microdilution technique. Antimicrob Agents Chemother 16: 710-718.

Di Santi, SM, Neves VLFC, Boulos M, Dutra AP, Ramos AMSV, Santos M, Barata LCB 1988. Avaliação da resposta do Plasmodium falciparum à cloroquina, quinino e mefloquina. Rev Inst Med Trop São Paulo 30: 147-152.

Fontanet AL, Johnson BD, Walker AM, Rooney W, Thimasarn K, Sturchler D, Macdonald M, Hours M, Wirth DF 1993. High prevalence of mefloquineresistant falciparum malaria in Eastern Thailand. Bull WHO 71: 377-383.

Fox E, Khalio AA, Sarwar M, Strickland GT 1985. Chloroquine-resistant Plasmodium falciparum: now in Pakistani Punjab. Lancet 1: 1432-1434.

FNS - Fundação Nacional de Saúde 1995. Lâminas positivas para malária. Brasil e Estado de São Paulo, 1965 a 1993, Superintendência de Controle de Endemias - SUCEN. Divisão de Orientação Técnica (D.O.T.). In AP Dutra, MCGP Alves, M Pereira, Relatório de Avaliação do Programa de Controle da Malária, Estado de São Paulo. Período de 1992 a 1994.

Kondrachine AV, Trigg, PI 1997. Global overview of malaria. Indian J Med Res 106: 39-52.

Kremsner PG, Zotter GM, Feldmeier H, Graninder W, Kollaritsch M, Wiedermann G, Rocha RM, Wernsdorfer WH 1989. In vitro drug sensitivity of Plasmodium falciparum in Acre, Brazil. Bull WHO 67: 289-293.

Le Bras 1995. La situation des chimioresistances du paludisme en Afrique. Med Trop 55: 9S-13S.

Marques AC 1986. Migrations and the dissemination of malaria in Brazil. Mem Inst Owaldo Cruz 81: 17-30.

Marques AC 1993. Dados epidemiológicos de malária na Amazônia, por município. Rev Soc Bras Med Trop 26: 43-59.
Nevill CG, Ochen, K, Munafu, CG, Bekobita, D, Sezi, CL 1995. Response of Plasmodium falciparum to chloroquine and Fansidar $^{\mathrm{R}}$ in vivo and chloroquine and amodiaquine in vitro in Uganda. East Afr Med J 72: 349-354.

Oduola AMJ, Milhous WK, Salako LA, Walker O, Desjardins RE 1987. Reduced in-vitro susceptibility to mefloquine in West African isolates of Plasmodium falciparum. Lancet 2: 1304-1305.

Souza JM 1992. Epidemiological distribution of Plasmodium falciparum drug resistance in Brazil and its relevance to the treatment and control of malaria. Mem Inst Oswaldo Cruz 87: 343-348.

Sowunmi A, Odoula AMJ, Salako LA, Ogundahunsi OAT, Laoyce OJ, Walker O 1992. The relationship between the response of Plasmodium falciparum malaria to mefloquine in African children and its sensitivity in vitro. Trans $R$ Soc Trop Med Hyg 86: 368-371.

Suebsaeng L, Wernsdorfer WH, Rooney W 1986. Sensitivity to quinine and mefloquine of Plasmodium falciparum in Thailand. Bull WHO 64: 759-765.

Warsame M, Wernsdorfer WH, Payne D, Bjorkman A 1991. Sussceptibility of Plasmodium falciparum in vitro to chloroquine, mefloquine, quinine and sulfadoxine/pyrimethamine in Somalia: relationships between the responses to the different drugs. Trans $R$ Soc Trop Med Hyg 85: 565-569.

Warsame M, Wernsdorfer WH, Willcox M, Kulane AA, Bjorkman A 1991. The changing pattern of Plasmodium falciparum susceptibility to chloroquine but not to mefloquine in a mesoendemic area of Somalia. Trans $R$ Soc Trop Med Hyg 85: 200-203.

Webster HK, Boudreau EF, Pavaqand K, Yongvanitchit K, Pang LW 1985. Antimalarial drug susceptibility testing of Plasmodium falciparum in Thailand using a microdilution radioisotope method. Am J Trop Med Hyg 34: 228-235,

Wernsdorfer WH 1992. The biological and epidemiological basis of drug resistance in malaria parasites. Southeast Asian J Trop Med Public Health 23: 123-129.

Wolday D, Kibread T, Bukenya D, Hodes R 1995. Sensitivity of Plasmodium falciparum $n$ vivo to chloroquine and pyrimethamine-sulfadoxine in Rwandan patients in a refugee camp in Zaire. Trans $R$ Soc Trop Med Hyg 89: 654-656.

Wongsrichanalai C, Webster HK, Wimonwattrawatte T, Sookto P, Chuanak N, Thimarsan K, Wernsdorfer WH 1992a. Emergence of multidrug-resistant Plasmodium falciparum in Thailand: in vitro tracking. Am J Trop Med Hyg 47: 112-116.

Wongsrichanalai C, Webster HK, Wimonwattrawateen T, Sookto P, Chuanak N, Timasarn K, Wernsdorfer WH 1992b. In vitro sensitivity of Plasmodium falciparum isolates in Thailand to quinine and chloroquine, 1984-1990. Southeast Asian J Trop Med Public Health 23: 533-536.

Zalis MG, Pang L, Silveira MS, Milhous WK, Wirth DF 1998. Characterization of Plasmodium falciparum isolated from the Amazon Region of Brazil: evidence for quinine resistance. Am J Trop Med Hyg 58: 630-637. 